AUSTRALIAN JOURNAL OF BASIC AND
ASSN:1991-8178
EISSN: 2309-8414
DOI: $10.22587 /$ ajbas.2017.11.14.15
Journal home page: www.ajbasweb.com

\title{
Which one is the Basic Source! The Cyclop of Homer or the Cyclop of Dede Korkut (Tepegöz)? The First Part*
}

\author{
${ }^{1}$ Hasan Gunes, ${ }^{2}$ Nadide Gunes, ${ }^{3}$ Ferdi Bozkurt, ${ }^{4}$ Gulcan Cakır. \\ ${ }^{I}$ Turkish Folk Literature Associate Professor at the Anadolu University, Eskisehir, Turkey. \\ ${ }^{2}$ English Teacher at the Sucaaddin Veli IOO, Eskisehir, Turkey. \\ ${ }^{3}$ Turkish Folk Literature, Assistant Prfessor at the Anadolu University, Eskisehir, Turkey. \\ ${ }^{4}$ Faculty of Education, German language and Literature, Assistant Prfessor at the Anadolu University, Eskisehir, Turkey.
}

\section{Address For Correspondence:}

Hasan Gunes, Turkish Folk Literature Associate Professor at the Anadolu University, Eskisehir, Turkey.

E-mail: hasangunes32@hotmail.com.

\section{ARTICLE INFO}

\section{Article history:}

Received 12 October 2017

Accepted 22 November 2017

Available online 6 December 2017

Keywords:

Heinrich Friedrich von Diez, Tepegöz,

Homer Cyclop or Oguz Cyclop

\begin{abstract}
A B S T R A C T
Background: The Dede Korkut epic stories are one of the most important sources that reflect our own culture on our present day. For now there are two samples of these due epics that have been transferred up today. One of them is the Vatikan Sample by Ettori Rossi and the other one the Dresden Sample by Heinrich Friedrich von Diez.In this samplea writing takes place "Der neuendeckte oghuzische Cyklop verglichen mit dem Homerischen" that can be translated as"The Comparison of the newly found Oghuz Cyklop with that of Homer". There are two important identifications made in this work translated by us. One of them is the identification of the era in which Dede Korkut might have lived and the other is the fact that the Greek Cyclop was inspired by the Cyclop of the Oghuz. Objectıve: As it is known there are some debates about the issues of the roots of the Greek Cyclop and the Cyclop of the Oghuz and to which culture they belong. To which culture the Cyclop belongs toas an issue will be enlightened with this manuscript in fact. Though Diez experienced some misunderstandings in comprehending particular words in fact he reflected the text $\% 99$ truely. The words being misunderstood by him hadn't affected the general meaning at all. To identify this conclusion the comparative method has been used as a method in the manuscript of ours. Results: In comparing the Cyclop taking place in the Greek Mythology, that is comparing the Greek Cyclop and the Cyclop of the Oghuz, this work reveals the fact that the Greek Cyclop was inspired by the Cyclop of the Oghuz and thus comes to the conclusion that it was copied from this original.
\end{abstract}

\section{INTRODUCTION}

The Dede Korkut Epic stories that are a part of the Epics of Oghuz are one of the most important sources that reflect the original culture of the Turkish Nation, (Gunes, 2016) that is our own culture.

For now there are two samples of these due epics that have been transferred up today. One of them is the Vatikan Sample by Ettori Rossi and the other one the Dresden Sample by Heinrich Friedrich von Diez.

Diez published two books in 1811 and 1815 he titled as "Denkwürdigkeiten von Asien". In the first of the books (1811) that of which consists of about 1500 pages, there is a writing that can be translated as "The Book of Oghuz" placed on page 157 of chapter IX of the book "Buch des Oghuz" (Gunes, 2016). The due book consists of 49 pages, in which information is given in the first nine pages and 200 sayings placed on the remaining pages. There are two manuscripts placed in the second book of his that was published in 1815 . The first of them is "Buch des Oghuz von Dede Korkut" that can be translated as "Book of the Oghuz by Dede Korkut" and is placed on pages 288-331 of chapter 7 . In the same book on pages 399-457 of chapter 14, a writing takes place "Der neuentdeckte oghuzische Cyclop verglichen mit dem Homerischen" that can be translated as "The comparison of the newly found Cyclop of Oghuz with that of Homer" (Gunes, 2015).

\section{Open Access Journal \\ Published BY AENSI Publication}

(C) 2017 AENSI Publisher All rights reserved

This work is licensed under the Creative Commons Attribution International License (CC BY). http://creativecommons.org/licenses/by/4.0/ 
We will deal upon the third manuscript within the due three manuscripts. There are important identifications in this work translated by us. Diez is writing about the Cyclop in the work of Homer named Odyssee as being inspired by the Cyclop of the Oghuz (Tepegöz of Oghuz). In comparing the Cyclop taking place in the Greek mythology, that is comparing the Greek Cyclop of the Oghuz, this work reveals the fact that the Greek Cyclop was inspired by the Cyclop of the Oghuz and thus comes to the conclusion that it was copied from this original.

Since it is of utmost significance, the due manuscript is considered to be published by us in two parts. That is; Diez had been able to gather a good amount of knowledge on the subject about the Cyclop. And in our opinion he had translated it truthfully the same. But however in translating the text to German from the language of the Ottoman's (Osmanlica) he made some misunderstandings. So as a result, in the first part of the manuscript it will be dealt upon the misunderstandings (Gunes, 2015) Diez made while translating and it will be our endevour to reveal the differences between the Cyclop of Homer and the Cyclop of the Oghuz in detail by trying to reflect the point of view of Diez continiuosly.

\section{The Misunderstandings Diez, Made:}

The"Denkwürdigkeiten von Asien Erster Teil" (Diez, 1811) which Heinrich von Diez named as the first part in 1811, was published by the publishing house and the year of publishing as it is labelled below. And the second part of the due work that was published in 1815 named "Denkwürdigkeiten von Asien Zweiter Teil" (Diez, 1815) was published by another publishing house that is also labelled below.

The study of Diez which is the subject of our examination at the moment, placed in the first part from page 157 onwards in his book called "Denkwürdigkeiten von Asien 1 first part" is all about Dede Korkut. The due work named as "IX. Book of Oghuz" consists of 49 pages.

And in the second part of the mentioned book there are two more studies related with Dede Korkut. The first of them is "Buch des Oghuz von Dede Korkud" placed in the 7 th part, between the pages 288-331 and the second one is the study with the title of "Der neuentdeckte oghuzische Cycklop verglichen mit dem Homerischen"placed in the 14 th part, between the pages 399-457. Diez, especially in his last study about the Cyclop was delivering messages of utmost importance, sending references to our present day from 200 years ago. In the statement placed in his due work on pages $418-419$ (DİEZ, 1815).

Von Diez is expecting a few words of thankfulness with his words starting with "there might be people even though not many who would wish to take benefit of this work and wish to deliver their thankslongafter my generation, in regard ofthis probability,enlightening the darkness of the antiquity would not be an endevour made in vain". And we, by translating the due text are in fact delivering our thanks and gratefulness to Heinrich Friedrich von Diez from the heart.

First of all while translating the work of Diez the toughness of the language used in this text, his usage of extremely long sentences, hisreturnings to the daily language now and then by losing the impact on the plot, his changing the time of the sentence as a result of his returnings to the daily language, and the faults that Diez made as an outcoming of his miscomprehension (which are also constructing the theme of our manuscript), has taken place as the most significant difficultiesin translating the due work into Turkish. From this point of view, a clarification has been revealed to the fact of this text remaining untranslated for 200 years, due to the fact of possesing a highly hard level of language usage. In the due study of ours we are going to focus on the faults Heinrich Friedrich von Diez made in his translation of the Cyclop.

\section{The Faults Heinrich Friedrich von Diez made in the Translation of the Cyclop:}

In the due work of Diez there is a mistake in the usage of the Word "Fels", on page 400 (DIEZ, 1815). The meaning of the Word "Fels" is "rock". Whiletranslating, Diez interpreted the Word "kayı" as "kaya". But in fact the intended word in the original text was "Kayı Boyu" not "kaya" (rock). "Kayı" (is first of all a proper noun) "Boy" means literally (a branch of a race ) so "Kayı Boyu" is a branch of the race of the Turks.

When the due text is translated it can be seen that a very meaningless statement occurs as a result of the misinterpretation and misplacement of the word "kaya" (rock), "Korkut Ata spoke with his decisive manner: The sovereignity will pass over to a Kayı, in its final eras,again, noone will be capable of taking this power from the Kayi". With the statement "it will last until the doomsday comes" the generation of Ottoman, which is present and will continue to be present, was meant.

\section{The 2 nd Word that was misunderstood:}

Onpage 401 (DİEZ, 1815)of his book "Denkwürdigkeiten von Asien" Diez used the word "Unfaelle" that means literally "accidents". In the original text of Dede Korkut this Word is "gaza" that literallymeans"battleship" or "war". So Diez translated the word "battleship" into German as "accident" by misunderstanding. 


\section{The 3 rd Word that was misunderstood:}

On page 402of his due book(DİEZ, 1815) Diez understood the statement “...Oğuznameyi düzdü" as "Oguzname", that is, he misunderstood and thus misinterpreted it as a word meaning "The book of Oghuz". As a matter of fact he hadn't been able to differentiate "Oğuzname" (that literally means "The Book of Oghuz") from "Oğuzname düzmek" that is "soylamak" (that literally means"singing songs in order to praise the generation of Oghuz")

\section{The 4 th Word that was misunderstood:}

As it can be seen on page 403of his Book (DİEZ, 1815) "Denkwürdigkeiten von Asien" Diez named the Greek one as "Cyclop", and now and then he also named Tepegöz as "Cyclop". And this situation arises some misunderstandings in the further pages.

\section{The 5 th Word that was misunderstood:}

On page 404 (DİEZ, 1815)of his due book Diez says "Dede Korkut was also summoned" after Tepegöz had been killed byBissat (in fact "Basat") to sing brand new joyful songs and to deliver his best wishes." But in fact in the original text, there is not a"folc song" but a "soylama" (praising the generation of Oghuz with all its descendants) as we also mentioned above. In another work of his, in interpreting the word "soylama" Diez says"these kinds of statements that I am unable to give a meaning to, occur many times in the text" and by saying so he revealed the fact that in real he had no idea of what "soylama" could in fact mean.

\section{The 6 th Word that was misunderstood:}

On page 411 of the due work,(DİEZ, 1815) the statement "...umdessen hinterher beraubt zu werden" should have been translated as "claiming possession later on" But nevertheless in the statementthe written form and its real meaning is different. In fact in the original text the word was meant not as "steal" but "claiming possession"

In the due translation of the text - whether true or false- both of the Cyclops, as they were described by Homer and Ricci, were introduced as one eyed in order to be able to claim possession on them. No matter how many documents Ricci had put forward to rectify their being one eyed,its truthfulness isn't of our interest, since these are the Cyclops that are not our concern. And the facts that are desired to be explained will be understood in the further pages. See "Tepegözthe original text".

\section{The 7 th Word that was misunderstood:}

On page 414 of his due book (DİEZ, 1815) Diez used the expression"Tepegöz shouts in such a waythat even the mountainsecho " just very after the expression "He keeps waiting for his falling asleep in order to burn and extract his eye ". This sudden transition is not the fault of the translator's but of itsbeing mentioned in the same sequence within the original text, that belonged to Diez.

In the translation of the due part the following expressions take place "Bissat (Basat), after falling to the position of a defender from an attacker," learns from the two servants of the Cyclop that he can be woundedonly by its eye. Thereafter he heatsa big knife (a battle knife) on the fire and starts waiting for theCyclop's falling asleep in order toburn and extract his eye. Tepegöz shouts so violently and loudlythateven the mountains echo". The parts left between the expressions were whether skipped by Diez or were also lacking in the original text.

\section{The 8 th Word that was misunderstood:}

On page 420 of the book (DIEZ, 1815) Diez misunderstood and misinterpreted the Word"peri "(fairy)and used the Word"engel" that means (angel) instead of the word "peri" (fairy). In fact "engel" has the meaning "angel". But according to the book of Dede Korkut the true meaning is "peri"(fairy).

The due part can be translated as such: "there was a water fountain known to be as "uzun pinar" (long stream ).Fairies gathered around this waterfountain. With their one glance the sheep got annoyed. The shephard hit the goat leading the herd of the sheep that was also annoyed and headed the scared herd again towards the stream".

\section{The 9 th Word that was misunderstood:}

Diez also misinterpreted "uzun pinar" as"Lange Quelle" - that literallymeans"long fountain".For the translation of (uzun pınar) "langer brunnen" would have been a much better one (DİEZ, 1815) P: 420.

On page 420 of the due book (DİEZ, 1815) the statement "er begehrtedesselben" draws our attention. The meaning of this statement of his is "he did the same himself", that is,Diez is hinting on the sexual intercourse of the fairies and that the shephard did the same himself. This can be understoodby the expression "er sah, dass die Engelmaedchen Flügelanbanden"

It probably would have been much better if the above mentioned part had been translated as such: "the shephard took off thefelt from his shoulders, threw it over them and caught one of the fairies.He ran after her 
and desired her rapidly. In the meantime the sheepstarted to run around again.But the shephard kept running in front of the fairy in order to gather the sheep".

The 10 th Word that was misunderstood:

Another word that was misinterpreted here is "Engelmaedchen"-"female angels" that literally means "dişi melek" in Turkish. Here the notion of fairy and angel had been completely misunderstood.

\section{The 11 th Word that was misunderstood:}

On page 420 of his book (DİEZ, 1815) Diez introduced "the blonde shephard" as "bey" that means literallyleader of thechieftain. But in reality there is no such situation.

\section{a) Sari Tschoban ist Beyname und heist nach "den Worten: gelber Hirte.}

\section{The 12 th Word that was misunderstood:}

On the same page the word "reisemantel" that literally means "travelling coat" in German(in the original text "kepenek") had been mistranslated (DİEZ, 1815) P: 420. Of course we canunderstand that the word "kepenek" in the original text of Dede Korkut with the meaning "felt" was not a known thing in German culture. But ifthe words "felt" also"...felt" in Englishor"filz" "cloak" being not foreign alsoto the German language andculture instead of "reisemantel",had been used in the translation, that would have been a much better choice. Or seeking the easiest way "hirtenmantel" (shephard coat) would have been a better translation.

\section{The 13 th Word that was misunderstood:}

On page 426 Diez (DİEZ, 1815) used the punctuation in a wrong place."He stood up in the tent and said: I enclosed the Cyclop from the sky and I couldn't seize him. Bissat (Basat) the Black Tiger stepped forward and spoke: I enclosed the Cyclop in the Black Mountains (Karadağlar) but couldn't catch him. Bissat (Basat) (the Kygan Aslan)

Stood up and spoke:I enclosed the Cyclop with the harmony of the spheres of sky but couldn't catch him. Bissat! If you are a man, then ..."

If attention is paid to the translation, there is a fullstop before Bissat. In this way a notion occurs as if Bissat is the beginning of the other sentence. And thisresultsin misunderstandings like "Bissat, the Kygan Aslan (Kayhan Aslan) stood up"

But in fact it should have been as such:

He stood up in the tent and said: I enclosed the Cyclop from the sky and couldn't get seize of him, Bissat. The Black Tiger (Kara Kaplan) stepped forward and spoke: I enclosed the Cyclop in the Black Mountains (Karadağlar) but couldn’t catch him, Bissat. Kygan Aslan (Kayhan Aslan) stood up and spoke: I enclosed the Cyclop with the harmony of the spheres of sky but couldn't get seize of him, Bissat!

If you are a man, then..."

\section{The 14 th Word that was misunderstood:}

On page 431 of the book (DİEZ, 1815) the statement "kınlı ve kınsız kılıç" (sword with sheath or sword without sheath) was understoodby Diez as "bloody or unbloody sword" and thus was misinterpreted. The related part in the translation:

D.G. (Depe Ghöz) There is no death for you from now on. Have you seen that cave over there?

B. (Bissat) Yes, I have seen it.

D.G. There are two swords same with eachother. One of them bloody, the other one unbloody. The unbloody one cuts off my head. Go, take it and cut off my head.

\section{The 15 th Word that was misunderstood:}

On page 431 of the book(DİEZ, 1815) there is no translational mistake made related with Bissat's putting his sword again in its sheath although it had been split into two. It's being stated thusis because of Diez's misunderstanding.

The related part could have been translated as thus: “...he takes out his own sword and holds it towards the other sword that is hung on the wall. His sword suddenly splits in two. He grabsa piece of wood and holds it towards the sword. Also the piece of wood splits into two. Thereafter Bissat takes his bow and holds it towards the chain the sword is connected to.The sword splits both the bow and the chain itself is connected to into two. The sword falls down on the groundand gets dug in the ground. Bissat puts his own sword into itssheath -(There is no translational mistake in his later on putting his sword into its sheath although it had been split into two, although in fact his own sword was split into two. In the Book of Dede Korkut this part was expressed just the same, and Diez took the expression by its word, without making any alterings)- and grabs the sword that fell on the ground (the other sword) strongly and pulls it off the mud-(Of course we are talking here about a work that 
had been fictioned. But no matter how much it had been fictioned it has to bear a consistency within itself. The bloody sword had a feature Of cutting everything when it was first touched. As for Bissat could pull it off the mud with his own sword, had the sword lost its power when it fell on the ground and got dug in it? In this situation it can be questioned how the sword regained its power in order to cut off the Cyclop's head. Most probably some texts in the original book of Dede Korkut had been missing) -and turns back.

In fact Diez realised that something was lacking here and tried to correct his own mistake by giving related footnotes. "Here, there must have been some missing parts, in the original text, as for nothing had been stated about whether Bissat saw the second sword that was supposed to be bloody. But nevertheless Bissat's

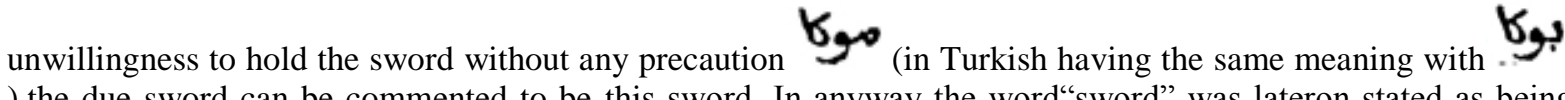
),the due sword can be commented to be this sword. In anyway the word"sword" was lateron stated as being touched with a piece of wood and bow by Bissat. After the expression "It is possible that the sword being touchedis the bloody sword" comes another statement that louds as such: "Here, of course we are talking about a fictional work. But no matter how fictional it is, it has to bear a consistency withinin itself". The bloody sword had a feature to cut everything when it was touched. As for Bissat could pull it off the mud with his own sword, had the sword lost its power when it fell into the mud? In this situation it can be questioned how the swordregained its power in order to cut off the Cyclop's head. Most probably some texts in the original book of Dede Korkut had been missing".

\section{The 16 th Word that was misunderstood:}

On page 433 of the book (DIEZZ, 1815)there is a sentence taking place that sounds as:

In the due sentence the expression "nun bruder" can be translated as "now brother" ("şimdi kardeş" in Turkish)(DİEZ, 1815) P: 433. But if the expression had been used as "nunsindwir brüder" the outcome would mean "now we are brothers", ("şimdi kardeşiz" in Turkish) and this would most certainly be the most correct interpretation. It seems that Diez had missed the expression "now we are brothers". A situation that draws our attention far more is the footnote that takes place at the end of the sentence.

In this footnote Diez said “in the original form of the text it is stated that: Don't kill my brothers (benim kardeşlerimi öldürme(in Turkish) that means(Tödte mir nicht die Brüder). But this doesn't possess a meaning at all, it doesn't even have a coherence and harmony with the following sentence. That's why I am considering this sentence mistakeful. And so I translated the sentence just as I read it”.

\section{Conclusion:}

When the due mistakes are examined it can be seen that the main characteristics of the book are truely revealed. The writings of Heinrich Friedrich von Diez were translated by us and it was seen that Diez generally conveyed the translation truthfully. Nevertheless when the conditions of the due era are taken under consideration it can be possibly claimed that the due mistakes are the outcomings of pure misunderstandings. Even if we accept the above mentioned misunderstandings as faults we share this common opinion about their bearing trivial importance besides the important knowledge Diez had delivered. As a matter of fact Diez's proving the fact that the Greek Cyclop was inspired by the Cyclop of the Oghuz by following the scientific and logical hints he had put forward himself in comparing the Cyclop renowned to be that of Homer's with the Cyclop of the Oghuz (Tepegöz) is a very valuable and crucial detail. Diez examined both of the works very deeply, he even conveyed it in detail so that he could retell the work to the whole World in German, and as a result he had been able to explain the differences between the two works, their sources and the ways of their spreading.

Due to the fact that the text being too long, it has been structured into two parts by me so that it can be conveyed in the formation of a manuscript. For that reason the source of the Cyclop of the Oghuz and the ways of its spreading will be explained in detail in the second part. While dealing with the Cyclop of the Oghuz in detail, the fact will also be revealed that the Cyclop of Homer in other words the Cyclop of the Greek was lacking in in its roots and source. In the due second part of the manuscript titled as "Der neuentdeckte oghuzische Cyclop verglichen mit dem Homerischen" and that was published in 1815 in the name of Heinrich Friedrich von Diez in the book "Denkwürdigkeiten von Asien, zweiter Teil, on pages 399-457, will be tried to be conveyed. The due manuscript is an important work and is forming the background of this work of ours. As to the sequence it is considered more appropriate by me conveying the errors first and giving the main text afterwards. In this way a much better perception is headed for.

As a result we must stand as a protector of Diez's works and we claim that it is a must to translate his work named "Denkwürdigkeiten von Asien" as a whole. The task of translating the due work is crucial in following the footsteps of our ancestors and the same a national duty of ours. 


\section{REFERENCES}

GÜNEŞ, H., 2015. “Tepegöz veya Oğuz Cyklopu”, Milli Folklor, S. 107, ss. 161-183, Ankara.

GÜNEŞ, H., 2016. The book of speeches, reflects speeches of the ancestors and is know as the book of Oghuz Taken from the Tatar-Turkish, Millî Folklor, 28(109): 257-260.

VON DIEZ H, F., 1811. Denkwürdigkeiten von Asien, In Commission der NicolaischenBuchhandlung.

VON DİEZ Heinrich Friedrich, 1815. Denkwürdigkeiten von Asien, In Commission der HalleschenWaisenhaus- Buchhandlung, Berlin: und Halle, pp: 399-457.

TUNÇ Gökhan, 2007. "The Evaluation of Yunus Emre in the Notion of Fakelore”, Milli Folklor, 75: 17-23. 